\title{
A Novel Type of SYT/SSX Fusion: Methodological and Biological Implications
}

Maria Törnkvist, M.Sc., Bertha Brodin, Ph.D., Armando Bartolazzi, M.D., Ph.D., Olle Larsson, M.D., Ph.D.

Department of Cellular and Molecular Tumor Pathology, Cancer Centrum Karolinska, Karolinska

Hospital (MT, BB, AB, OL), Stockholm, Sweden; and Department of Pathology, Regina Elena Cancer

Institute $(A B)$, Rome, Italy

Synovial sarcoma (SS) is a rare soft-tissue tumor that affects children and young adults. It is characterized by the chromosomal translocation $t(X$; 18)(p11.2;q11.2), which results in the fusion of the SYT gene on chromosome 18 with a SSX gene on chromosome $X$. In the majority of cases, SYT is fused to exon 5 of SSX1 (64\%), SSX2 (36\%), or, rarely, SSX4. A novel fusion transcript variant deriving from the fusion of SYT to exon 6 of SSX4 gene (SYT/SSX4v) was found coexpressed in one of the previously reported SYT/SSX4 cases. In the present investigation, we describe a new SS case that was previously shown to be negative for SYT/SSX1 and SYT/SSX2 expression by conventional reverse transcription polymerase chain reaction (RT-PCR) methods. By redesigning and optimizing the RTPCR protocol, we were able to detect SYT/SSX4V as the sole fusion transcript expressed in this tumor sample. This finding suggests that this novel fusion gene, which involves exon 6 of SSX only, is sufficient to keep the transforming function conferred by the SYT/SSX translocation of SS. In about 3\% of morphologically, ultrastructurally, and immunohistochemically defined SS, the SYT/SSX fusion transcript is not detected using conventional RT-PCR. Here we demonstrate that optimization of the RTPCR method is important for detecting different and unexpected SYT/SSX variants, which otherwise could be overlooked. Using nine cases of SS in which SYT/SSX fusion transcripts were not detected by conventional RT-PCR methods, we demonstrate

Copyright (C) 2002 by The United States and Canadian Academy of Pathology, Inc.

VOL. 15, NO. 6, P. 679, 2002 Printed in the U.S.A.

Date of acceptance: January 22, 2002.

This project was supported by grants from the Swedish Cancer Society, the Stockholm Cancer Society, and the Swedish Children Cancer Society. MT is a recipient of a Ph.D. student fellowship from the Swedish Foundation for Strategic Research. $\mathrm{AB}$ is guest researcher of the Swedish Cancer Society and has also been supported by the Italian Association for Cancer Research (A.I.R.C.) and by the Yamagiwa Yoshida award from the Union Internationale Contre le Cancer.

Address reprint requests to: Bertha Brodin, CCK R8:04, Karolinska Hospital, SE 17176 Stockholm, Sweden; e-mail: bertha.brodin@cck.ki.se; fax: $+46-8-321047$. the presence of SYT/SSX transcripts in two cases using the proposed RT-PCR approach. Applications of optimized RT-PCR can contribute to reduce falsenegative SYT/SSX SS cases reported in literature.

KEY WORDS: RT-PCR, Synovial sarcoma, SYT/SSX fusion gene, SYT/SSX variants.

Mod Pathol 2002;15(6):679-685

Synovial sarcomas (SS) account for 7 to $10 \%$ of all human soft-tissue sarcomas and are mainly located in the extremities in the vicinity of large joints (1). Depending on histomorphological appearance, SSs are usually subdivided into two major forms, biphasic and monophasic. Biphasic SSs are composed of both epithelial cells arranged in pseudoglandular structures and spindle cells, whereas the monophasic form/is generally composed of spindle cells alone without evidence of epithelial differentiation (1). SS is, regardless of histological subtype, genetically characterized by the chromosomal translocation $\mathrm{t}(\mathrm{X} ; 18)(\mathrm{p} 11.2 ; \mathrm{q} 11.2)(2,3)$, which is exclusively found in this malignancy $(4-8)$. The $t(X ; 18)$ leads to the fusion of the SYT gene on chromosome 18, and an SSX gene on the X chromosome $(9,10)$. The SYT gene-is widely expressed in normal human tissues (9). The SSX genes constitute a family of, so far, six known highly homologous genes, SSX1-6 (11-13), where SSX6 has been reported recently in the public human genome domain. A splice variant of SSX4 lacking exon 5 has also been reported (13). Despite the restricted expression of SSX genes to normal testis and, at lower levels, to the thyroid gland (4, 11 ), some of them are frequently found in human malignancies. This fact contributed to define SSX protein products as "cancer-testis antigens" (1315). The fusion gene involved in SS is most commonly composed of either SYT/SSX1 or SYT/SSX2. Only two cases of SYT/SSX4 have been reported to date $(16,17)$. We also recently isolated a novel fusion transcript variant involving the fusion of SYT to exon 6 of SSX4 (lacking exon 5), designated SYT/ $\mathrm{SSX} 4 \mathrm{v}$, found to be coexpressed with full-length 
SYT/SSX4 (18). Interestingly, it has been shown that in patients bearing SS, the expression of specific SYT/SSX fusion genes can affect the clinical outcome of this neoplastic disease. In fact, the expression of SYT/SSX1 transcript has been demonstrated to correlate with short metastasis-free survival and higher tumor proliferation rate, with respect to SYT/SSX2-expressing tumors (19-21). The relation between the expression of SYT/SSX4 variants and clinical outcome is not known because of the few identified cases so far. SSX3, SSX5, and SSX6 genes have not been found fused to SYT in SS (12).

Although SYT/SSX fusion gene is considered specific for SS, it has not been detected in about $3 \%$ of these lesions, despite morphological characterizations that define these tumors $(1,22)$. Here we report that optimization of the RT-PCR protocol for molecular analysis of SSs can at least in part resolve this issue. In fact, by this approach, we were able to detect unexpected SYT/SSX transcripts in cases of SS previously considered negative and to identify a new case of SS expressing exclusively the SYT/SSX4 variant (SYT/SSX4v) that lacks exon 5 of the SSX4 gene.

\section{MATERIALS AND METHODS}

\section{RNA Extraction and Reverse Transcription}

RNA was isolated from primary tumor sample histologically characterized as SS. Five-microliter total RNA was reverse transcribed with random nanomers (Amersham Pharmacia Biotech, Buckinghamshire, UK) according to standard procedures in a $20-\mu \mathrm{L}$ reaction mixture containing 500 $\mu \mathrm{M}$ dNTP each (PE Applied Biosystems, Foster City, CA) and using Enhanced AMV-reverse transcriptase (Sigma, Saint Louis, MO).

\section{Detection of SYT/SSX by PCR}

A nested PCR method was optimized for the detection of SYT/SSX fusion genes. Briefly, the outer PCR was carried out as shown in Figure 1A. For the specific detection of SYT/SSX1 and SYT/SSX2 a standard method (21) was used (Fig. 1B-C), using the primers previously reported $(4,10,11)$. We designed a nested PCR for the wide detection of all splice variants of SYT/SSX by optimizing the reaction conditions and introducing new sets of primers (SYT 343+ and SYT5) as described (Fig. 1A and D). Fusion transcripts containing exon 5 were detected by using a primer located in this specific region (Fig. 1E). All PCR reactions were carried out in accordance with the precautions previously described by Kwok and Higuchi (23). PCR products were separated in a $1 \%$ agarose gel containing ethidium bromide and were visualized in a Fluor-S
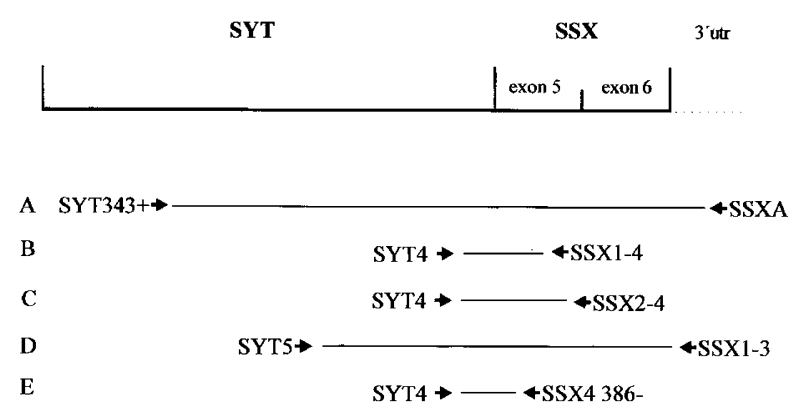

\begin{tabular}{|c|c|c|c|c|c|}
\hline & & \multicolumn{2}{|c|}{ METHOD } & \begin{tabular}{|l|} 
PRIMER \\
\end{tabular} & SEQUENCE \\
\hline & $\begin{array}{c}\text { OUTER } \\
\text { PCR }\end{array}$ & \multicolumn{2}{|c|}{ Optimized method } & & \\
\hline A & & $\begin{array}{l}\mathrm{MgCl}_{2}: 2 \mathrm{mM} \\
\text { dNTP: } 1 \mathrm{mM}\end{array}$ & $\begin{array}{l}94^{\circ} 30 \mathrm{sec} \\
50^{\circ} 1 \mathrm{~min} \\
70^{\circ} 1 \mathrm{~min}\end{array}$ & $\begin{array}{c}\text { SYT343+ } \\
\text { SSXA }\end{array}$ & $\begin{array}{l}\text { 5'-GGTGGGGGTCCTCCTGCACCG-3' } \\
\text { 5'-CACTTGCTATGCACCTGATG-3' }\end{array}$ \\
\hline & $\begin{array}{l}\text { INNER } \\
\text { PCR }\end{array}$ & \multicolumn{2}{|c|}{ Standard method } & & \\
\hline B & & $\begin{array}{l}\mathrm{MgCl}_{2}: 1.5 \mathrm{mM} \\
\text { dNTP: } 0.6 \mathrm{mM}\end{array}$ & $\begin{array}{l}94^{\circ} 30 \mathrm{sec} \\
63^{\circ} 1 \mathrm{~min} \\
70^{\circ} 1 \mathrm{~min}\end{array}$ & $\begin{array}{c}\text { SYT4 } \\
\text { SSX1-4 }\end{array}$ & $\begin{array}{c}5^{\prime} \text {-AGACCAACACAGCCTGGACCA-3' } \\
\text { 5'-GGTGCAGTTGTTTCCCATCG-3' }\end{array}$ \\
\hline \multirow[b]{2}{*}{ C } & & \multicolumn{2}{|c|}{ Standard method } & & \\
\hline & & $\begin{array}{l}\mathrm{MgCl}_{2}: 1.5 \mathrm{mM} \\
\mathrm{dNTP}: 0.6 \mathrm{mM}\end{array}$ & $\begin{array}{l}94^{\circ} 30 \mathrm{sec} \\
63^{\circ} 1 \mathrm{~min} \\
70^{\circ} 1 \mathrm{~min}\end{array}$ & $\begin{array}{l}\text { SYT4 } \\
\text { SSX2-4 }\end{array}$ & $\begin{array}{l}5^{\prime} \text {-AGACCAACACAGCCTGGACCA-3' } \\
\text { 5'-TCTCGTGAATCTTCTCAGAGG-3' }\end{array}$ \\
\hline \multirow[b]{4}{*}{ E } & & \multicolumn{2}{|c|}{ Optimized method } & & \\
\hline & & $\begin{array}{l}\mathrm{MgCl}_{2}: 2 \mathrm{mM} \\
\text { dNTP: } 1 \mathrm{mM}\end{array}$ & $\begin{array}{l}94^{\circ} 30 \mathrm{sec} \\
56^{\circ} 1 \mathrm{~min} \\
70^{\circ} 1 \mathrm{~min}\end{array}$ & $\begin{array}{l}\text { SYT5 } \\
\text { SSX1-3 }\end{array}$ & $\begin{array}{c}\text { 5'-CCTCCAGAAGGCATGAACC-3' } \\
\text { 5'-CTCGTCATCTTCCTCAGGGTC- } 3^{\prime}\end{array}$ \\
\hline & & \multicolumn{2}{|c|}{ Exon 5 specific method } & & \\
\hline & & $\begin{array}{l}\mathrm{MgCl}_{2}: 2 \mathrm{mM} \\
\text { dNTP: } 1 \mathrm{mM}\end{array}$ & $\begin{array}{l}94^{\circ} 30 \mathrm{sec} \\
60^{\circ} 1 \mathrm{~min} \\
70^{\circ} 1 \mathrm{~min}\end{array}$ & \begin{tabular}{|c|} 
SYT4 \\
SSX 386-
\end{tabular} & $\begin{array}{c}\text { 5'-AGACCAACACAGCCTGGACCA-3' } \\
5^{\prime} \text {-GCCTCTGGCACTTCCTTCAAACC-3 }\end{array}$ \\
\hline
\end{tabular}

FIGURE 1. Schematic presentation of the SYT/SSX fusion gene and locations of primers used for the reverse transcription polymerase chain reaction (RT-PCR). Overview of the PCR conditions used for the different PCRs are shown in the enclosed table. (A) Outer PCR used for all samples. (B-E) Inner PCRs (see Materials and Methods). (B) Inner SYT/SSX1-specific reaction. (C) Inner SYT/SSX2-specific reaction. All reactions were run for 30 cycles.

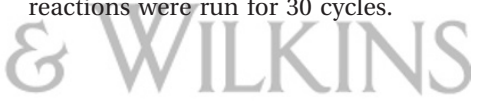

MultiImager System (BioRad, Hercules). PCR fragments were direct sequenced by cycle sequencing with dye-labeled terminators (BigDye Terminator Cycle Sequencing kit, PE Applied Biosystems) and analyzed on a DNA sequencer ABI PRISM 310 (PE Applied Biosystems).

\section{Cloning}

Cloning of SYT/SSX4v was carried out by seminested PCR amplification of DNA from the SS sample using primers spanning the start codon of SYT (SYT +1 : 5'-ATGGGCGGCAACATGTCTGTGG-3') and the 3' untranslated region of SSX (SSX 2-3: 5'-TGCTATGCACCTGATGACGA-3'and SSX 576-: 5'-ATTCGAGCTCGAATTCCYAGGGGAGTTACTCGTCA-3'). The product was visualized by ethidium bromide staining in a $1 \%$ agarose gel, purified using commercial PCR preparations (Wizard PCR preparations DNA purification system; Promega, Madison, WI) and cloned into pGEM-T (Promega). Clones containing the insert were screened by PCR using vector primers RIT 27 (5'-GCTTCCGGCTCGTATGTTGTGTG-3') and RIT 28 (5'-AAAGGGGGATGTGCTGCAAGGCG-3') and inner 
primers within the SYT/SSX sequence. Thereafter, full sequencing was performed for confirmation.

\section{RESULTS}

\section{Clinical History}

A 36-year-old woman was referred for pain in the right trochanteric region in 1994. Ordinary roentgenograms were performed, with no signs of pathology. Three years later, a new radiological investigation was performed. Radiographs showed a mass of $2 \times 3 \mathrm{~cm}$ localized deep in the subcutaneous tissue in apparent relation to the muscle. The radiological features as well as the slow growth of the lesion were considered compatible with a benign lesion, but unfortunately no biopsy was performed. A new radiological investigation was required in April 2000, showing a tumor mass $5 \times 6$ $\mathrm{cm}$ in size, which finally was resected surgically. The histological report was suggestive of SS. As a result, extended radical surgery was performed. Five months later, the patient underwent computed tomography assessment that showed multiple secondary lesions in the lung and suspected recurrence at the site of the primary tumor. We received frozen and formalin-fixed tissue samples for the molecular characterization of this tumor, here designated SS-I.

\section{Microscopic Description}

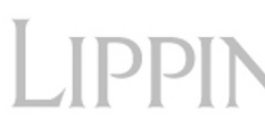

The reported lesion represented a classic biphasic SS in which both epithelial cells and fibroblastlike spindle cells were observed (Fig. 2A). Epithelial cells showed large vesicular nuclei and abundant pale-staining cytoplasm. Glandular structures and epithelial areas were clearly represented and were abundant in the same areas (Fig. 2A-E). The surrounding spindle cells consisted mostly of welloriented fibroblast-like elements of uniform appearance, with small amounts of indistinct cytoplasm and dark-stained nuclei. As reported in these tumors, cellular portions were alternated with less cellular areas in which collagen deposition and myxoid changes were visible (Fig. 2D-E). Immunostaining using antibodies to tissue-specific markers was also performed. There was a strong reactivity for vimentin and cytokeratin (especially in cells with epithelial differentiation) and instant slight reactivity for S-100 but negativity for muscular actin (data not shown). This immunoprofile is consistent with SS (1). Mitotic figures were scantily expressed. Solid and compact sheets of SS cells showing an active proliferation rate were detected immunohistochemically using an mAb to cyclin A (data not shown).

\section{Molecular Analysis}

Standard SYT/SSX1 and SYT/SSX2 RT-PCR reactions were carried out using previously reported specific oligonucleotide primers for SYT/SSX1 and SYT/SSX2 $(4,10,11)$, respectively, as reported in Figure 1B-C. We used these primers to detect the fusion transcript type expressed in the SS-I, but neither SYT/SSX1 nor SYT/SSX2 were detected in this sample (Fig. 3A-B). Well-characterized SS samples expressing SYT/SSX1, SYT/SSX2 or SYT/SSX4

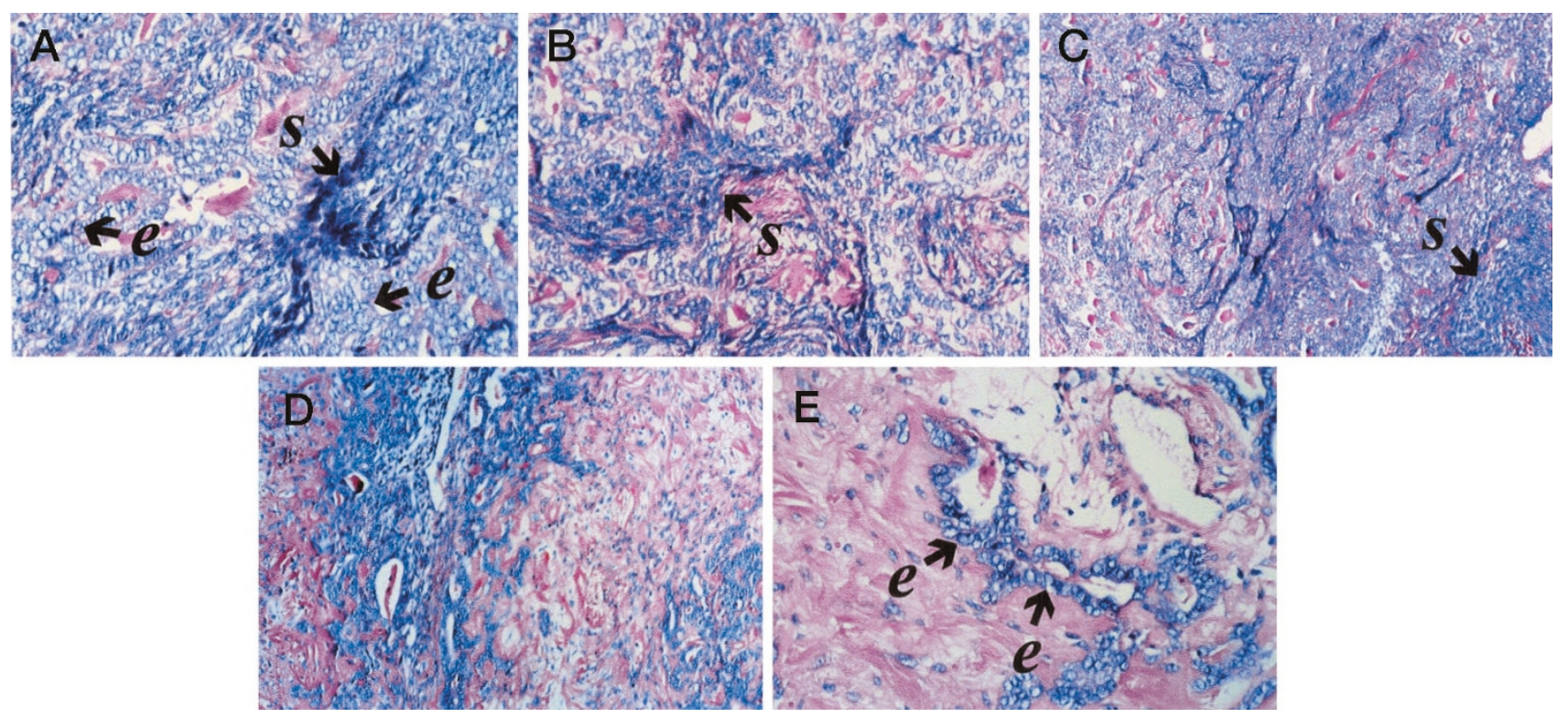

FIGURE 2. Histomorphological features of the synovial sarcoma (SS)-I considered in this study. Panels A-E show different aspects of this lesion. Glandular structures and epithelial cells (e) intermingled with spindle cells (s) are clearly identified. Biphasic appearance of the tumor is visible at higher magnification (A, B, E), as well as less cellular areas with collagen deposition and myxoid changes, which are frequent in SS (E). Conventional hematoxylin-eosin staining; magnification, $350 \times$ in $\mathbf{A}, \mathbf{B}, \mathbf{E}$ and $220 \times$ in $\mathbf{C}, \mathbf{D})$. 
were used as positive controls. As reported previously, SYT/SSX1- and SYT/SSX2-specific RT-PCR primers can also anneal SYT/SSX4 because of the mismatch of a few base pairs (17; Fig. 3A-B). Using an optimized nested RT-PCR amplification that includes outer and inner oligonucleotide primers specific for SYT sequences located far upstream from the fusion gene breakpoint, an outer SSX oligonucleotide primer specific for a sequence in the untranslated region, and an inner oligonucleotide primer at the 3'end of the SSX involved in the fusion gene (Fig. 1A and D), led to a robust detection of specific SYT/SSX fusion transcript in all tumor samples including the SS-I sample. In this analysis, we observed that the amplified fragment in SS-I was shorter than that of the control samples (Fig. 3C), suggesting the possibility to detect also SYT/SSX splice variants. The SS-I fragment was later shown to be shorter because of the lack of exon 5, as proved in an exon 5-specific PCR reaction (Fig. 3D). To determine the SYT/SSX fusion types and the specificity of the RT-PCR reaction (Fig. 1D), the amplified fragments from SS-I and controls (Fig. 3C) were isolated and sequenced. The sequence of the shorter fragment amplified from SS-I (Fig. 4B) was identified as the SYT/SSX4v that lacks exon 5 of the SSX transcript when analyzed against SYT/SSX sequences reported to GenBank. Attempts to clone the full-length cDNA of SYT/SSX4v were performed as described in Materials and Methods, but we were only able to isolate a partial cDNA clone (Fig. 4B). As a consequence of the lack of exon 5 in the SSX part, the predicted amino acid sequence was found to be different from the reported fusion gene transcript because of a shift in the open reading frame downstream of the breakpoint. Because the optimized RT-PCR method proved to be highly sensitive for the detection of SYT/SSX transcripts, we analyzed nine SSs previously shown to be SYT/SSX negative by conventional RT-PCR protocols (Fig. 5A
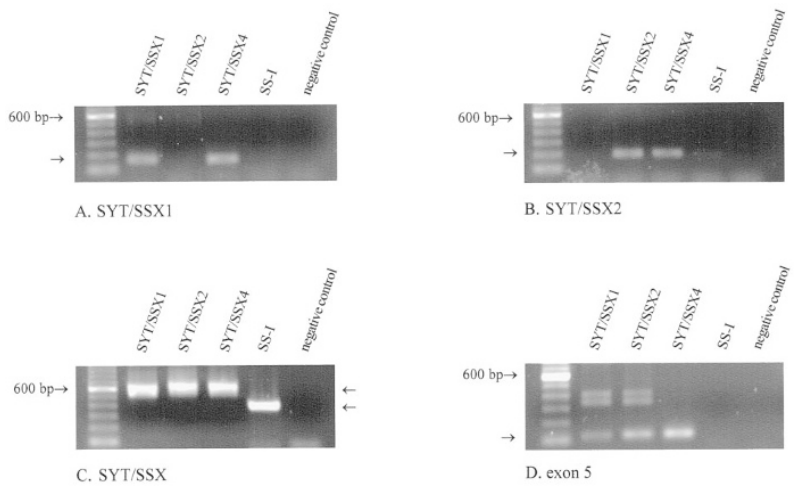

FIGURE 3. Reverse transcription polymerase chain reaction (PCR) fragments visualized by ethidium bromide-stained $1 \%$ agarose gel. (A) Standard SYT/SSX1 PCR. (B) Standard SYT/SSX2 PCR. (C) Optimized PCR method. (D) Exon 5-specific method. (For the oligonucleotide primers used in these amplifications, see table in Fig. 2).

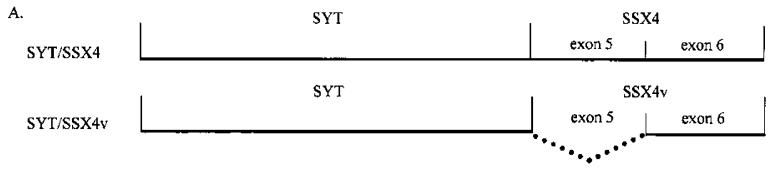

B.

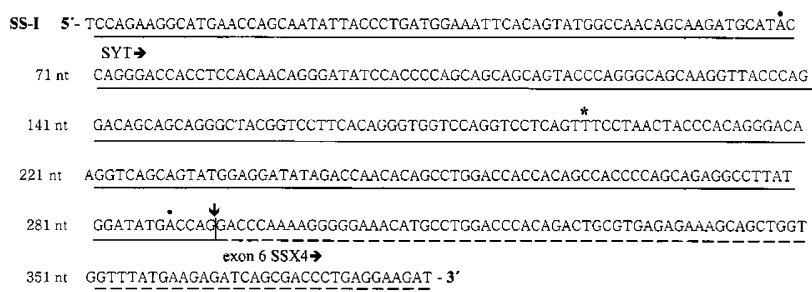

FIGURE 4. (A) Schematic presentation of full-length SYT/SSX4 fusion gene and SYT/SSX4v fusion gene lacking exon 5 (represented by the dotted line). (B) Partial cDNA sequence of the present case (SS-I). The arrow indicates the breakpoint between the SYT and the SSX. identifies the position in which the nucleotide is not in accordance with the SYT/SSX4v sequence reported to GenBank (Accession Number AF257501). * identifies the position in which the nucleotide is not in accordance with the SYT sequence reported to GenBank (Accession Number X79201).

and B). At least two of them were found to express SYT/SSX-specific transcripts (Fig. 5C). SYT/SSX amplicons were detected after only 20 cycles (Fig. 5D). Sequencing of the fragments in Figure 5C demonstrated that one of them (Fig. 5C, Lane 3) carried a SYT/SSX1 variant lacking $132 \mathrm{bp}$ (Exon 10) of the SYT gene and with the addition of $144 \mathrm{bp}$ (Exons 3 and 4) of the SSX1 gene. This splice variant has previously been described (11), and its schematic

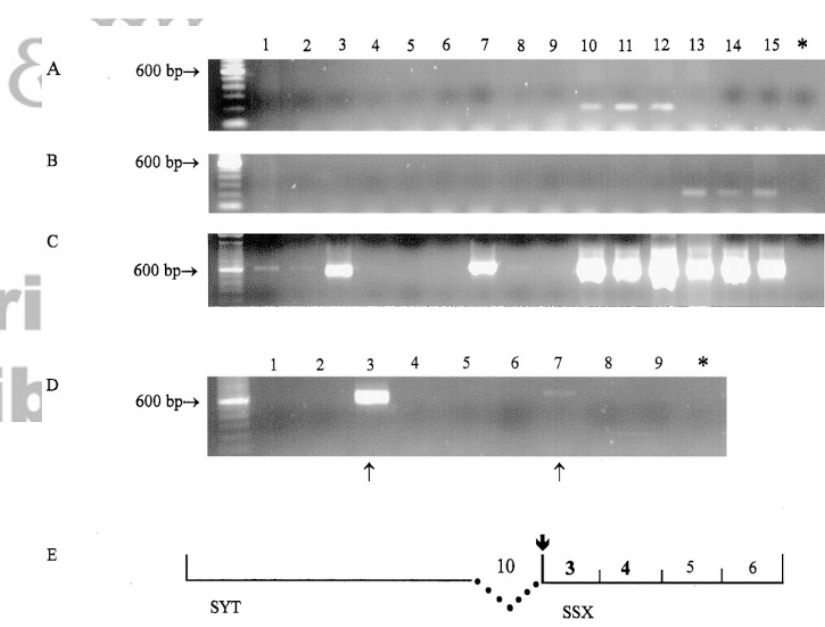

FIGURE 5. Reverse transcription polymerase chain reaction (PCR) fragments visualized by ethidium bromide-stained 1\% agarose gel. (A) Standard SYT/SSX1 PCR. (B) Standard SYT/SSX2 PCR. (C) Optimized PCR method (30 cycles). (D) Same optimized PCR method as in C but visualized after 20 cycles. The arrows indicate one strong band and one fade band visualized after 20 cycles. (E) Schematic presentation of the SYT/SSX1 variant (found in C Lane 3) lacking 132 bp (exon 10; dotted line) of the SYT gene and with the addition of 144 bp (exon 3 and 4; bold numbers) of the SSX1 gene. The arrow indicates the breakpoint between SYT and SSX. (For the oligonucleotide primers used in these amplifications, see table in Fig. 2). Lanes 1-9 represent SYT/SSX cases that were shown to be negative when using standard SYT/SSX1 and SYT/SSX2 methods; Lanes 10-12 represent classified SYT/SSX1 cases used as positive controls; Lanes 13-15 represent classified SYT/SSX2 cases used as positive controls; *negative control. 
presentation is shown in Figure 5E. The other SYT/ SSX-positive case was found to express SYT/SSX2 (Fig. 5C, Lane 7).

\section{DISCUSSION}

Despite the high homology between the six different SSX members, only SSX1, SSX2, and SSX4 have so far been found fused to SYT in the $t(18: X)$ translocation, which is considered to be specific for SS. Of 287 SYT/SSX-positive cases reported in the literature, about $64 \%$ express SYT/SSX1, and 36\%, SYT/SSX2 (reviewed in Ref. 24). Only two cases involving SSX4 have been reported to date $(16,17)$ in which co-expression of SYT/SSX4v was detected in the latter case (18). The present case of SS-I is a rare SS in which the sole expression of SYT/SSX4v transcript has been detected.

The difficulty in identifying new and/or unexpected fusion transcript variants expressed in SS, other than the fusion genes reported above, can be attributed to (1) a higher prevalence of SYT/SSX1 and SYT/SSX2 in the tumor samples that compete out the detection of rare variants in RT-PCR reactions; (2) differences in recombination sites of different SSX genes that increase the probability of rearrangements for SSX1 and SSX2 with respect to other SSX members; (3) poor optimization of the PCR methods in use that leads to the preferential detection of SYT/SSX1 and SYT/SSX2 fusion transcripts using specific primers restricted to SSX1 and SSX2 sequences. The coexistence of different splice variants of SYT/SSX fusion transcripts in SSs was recently described by our group (18), suggesting that subpopulations of cells expressing such fusion transcript variants might affect the present fusion gene classification of SSs.

An important aspect of the present study is represented by the fact that SYT/SSX4v is exclusively expressed in the reported lesion, suggesting that exon 5 of SSX, which is excluded in this gene fusion, may not be crucial for the malignant phenotype of SS. This is surprising because exon 5 has been proposed to be the most important part of the SSX involved in the transforming ability of SYT/SSX. The major base-pair differences between SYT/SSX1 and SYT/SSX2 are found within this exon (18 differences), together with several differences in potential phosphorylation and $N$-linked glycosylation sites (11). Exon 5 has therefore been suggested to be the region responsible for the biological and clinical differences between the two fusion gene variants SYT/SSX1 and SYT/SSX2 $(17,21)$. The absence of exon 5 in the present case could suggest that the "transforming potential" of SYT/SSX fusion protein is probably related to the SSX part codified by exon 6. Also, the SSXRD domain of SSX, which is respon- sible for repression of transcription (24), is located within this exon. This region has also been shown to be responsible for the nuclear distribution of SSX to the nucleus (25). Therefore, this part of SYT/SSX has been proposed to play a crucial role in SS development (26). However, this is contradicted by the finding of Sonobe et al. (27), in which an SS case carrying a truncated variant of SYT/SSX1, which lacks the $240 \mathrm{bp}$ of the 3 ' portion of SSX including the SSXRD, was identified.

Highest divergence in amino acid sequence between the SYT/SSX1 and SYT/SSX2 fusion proteins is found in a stretch of 35 amino acids (from amino acid 119 to 154). Within this region, called DD (divergent domain), there are 12 amino acid differences between the two sequences. Most of this domain is preserved in the truncated SYT/SSX1 variant reported by Sonobe et al. (27). This domain has therefore been proposed by dos Santos et al. (26) to be another critical domain for the oncogenic potential of SYT/SSX1. Interestingly, the DD is completely removed from the present case where SYT/ SSX4v is exclusively expressed. Moreover, as a consequence of the removal of exon 5 in SYT/SSX4v, which leads to a shift in the downstream open reading frame, the predicted amino acid sequence is different from other SYT/SSX fusion transcripts. This has also been predicted in the SSX4v sequence by Gure et al. (13), who state that the resulting 42 amino acids at the carboxy terminus, which are also included in the SYT/SSX4v, shows no homology to other SSX proteins.

These results suggest that the major malignant transformation potential of SYT/SSX lies within the SYT region of the fusion gene, or alternatively, it may result from the alteration of SYT normal function because of the addition of a nonspecific part of SSX. This is also indicated by the results presented by Nagai et al. (28), in which the responsible regions for transforming activity in SYT/SSX1 were examined using deletion mutants. Three different deletion mutants ( $\mathrm{dN}$ lacking 181 aa at the $N$-terminal region of SYT/SSX1 [within the SYT part]; dQPGY lacking 198 aa within the QPGY domain [within the SYT part]; and dC lacking 34 aa at the $C$-terminal end [within the SSX part]) were transfected into $3 \mathrm{Y} 1$ cells and plated into soft agar to examine the anchorage-independent growth. The only cells not able to form colonies of significant size were the SYT/SSX1-dN-expressing 3Y1 cells, indicating that deletion of the $\mathrm{N}$-terminal 181 amino acids of SYT/SSX1 causes loss of transforming capability. The same authors showed that the binding region of SYT/SSX1 to the chromatin remodeling factor $\mathrm{hBRM} / \mathrm{hSNF} 2 \alpha$, which regulates transcription and was shown to be essential for the SYT/SSX1-dependent transforming activity, was located within this amino acid stretch. However, de- 
spite the fact that wild-type SYT, which contains eight amino acids in the $C$-terminal that are lost when fused to SSX, was still able to bind hBRM/ hSNF2 $\alpha$, it did not have any transforming potential. This could indicate that some additional parts of SSX are essential for SYT to achieve the transforming activity of SYT/SSX in SS. However, further structural and functional analysis of SYT/SSX molecules will be necessary to better understand this issue.

Few molecular variants and spliced transcripts of the SYT/SSX fusion gene have been reported in literature $(4,11,18,27,29,30)$. However, the molecular characterization of these variants will contribute to better understanding the biological role played by SYT/SSX translocations, as well as the functional significance of the different portions of these chimeric proteins.

The SYT/SSX fusion transcript has not been detected in about $3 \%$ of SSs reported in the literature, despite morphological, ultrastructural, and immunohistochemical features that define these tumors ( 1 , 22). One possible explanation for this is that these cases represent fusion gene variants in which either the SYT or the SSX oligonucleotide primers used in the RT-PCR fail to bind specific cDNA regions because of differences in breakpoint location or alternative splicing. Re-evaluation of these cases using an optimized RT-PCR method may result in the isolation of novel SYT/SSX fusion transcripts, contributing to definitively clarify the possibility that the SYT/SSX fusion gene is necessary and sufficient for the origin and development of SS. In this work, we stress that it is not sufficient to use conventional SYT/SSX1- and SYT/SSX2-specific RT-PCR methods to fully characterize SS at molecular level. In fact, we demonstrate the expression of a rare SYT/SSX4 fusion gene in an otherwise RT-PCR-negative SS case, using an optimized RT-PCR approach. However, the use of consensus primers for SYT/SSX with SSX primers specific for the region including the 3 'end of exon 6 could miss fusion gene variants. This was illustrated by the truncated SYT/SSX variant described by Sonobe et al. (27), in which exon 6 was missing and the SS case was SYT/SSX negative by such RT-PCR approach. The unexpected fusion variant transcript was instead found using 3' RACE (27), which shows that careful attention is needed for identification of SSs when no fusion gene transcript can be found using conventional SYT and SSX primers for RT-PCR.

\section{REFERENCES}

1. Enzinger FM, Weiss SW. Synovial sarcoma. In: Enzinger FM, Weiss SW, editors. Soft tissue tumors. 3rd ed. St. Louis, MO: Mosby; 1995. p. 757-86.

2. Limon J, Dal Cin P, Sandberg AA. Translocations involving the $\mathrm{X}$ chromosome in solid tumors: presentation of two sarcomas with $\mathrm{t}(\mathrm{X} ; 18)(\mathrm{q} 13 ; \mathrm{p} 11)$. Cancer Genet Cytogenet 1986;23:87-91.
3. Turc-Carel C, Dal Cin P, Limon J, Rao U, Li FP, Corson JM, et al. Involvement of chromosome $\mathrm{X}$ in primary cytogenetic change in human neoplasia: nonrandom translocation in synovial sarcoma. Proc Natl Acad Sci U S A 1987;84:1981-5.

4. Fligman I, Lonardo F, Jhanwar SC, Gerald WL, Woodruff J, Ladanyi M. Molecular diagnosis of synovial sarcoma and characterization of a variant SYT-SSX2 fusion transcript. Am J Pathol 1995;147:1592-9.

5. Hiraga H, Nojima T, Abe S, Sawa H, Yamashiro K, Yamawaki $\mathrm{S}$, et al. Diagnosis of synovial sarcoma with the reverse transcriptase-polymerase chain reaction: analyses of $84 \mathrm{soft}$ tissue and bone tumors. Diagn Mol Pathol 1998;7:102-10.

6. Poteat HT, Corson JM, Fletcher JA. Detection of chromosome 18 rearrangement in synovial sarcoma by fluorescence in situ hybridization. Cancer Genet Cytogenet 1995;84:7681.

7. Willeke F, Mechtersheimer G, Schwarzbach M, Weitz J, Zimmer D, Lehnert T, et al. Detection of SYT-SSX1/2 fusion transcripts by reverse transcriptase-polymerase chain reaction (RT-PCR) is a valuable diagnostic tool in synovial sarcoma. Eur J Cancer 1998;34:2087-93.

8. Yang P, Hirose T, Hasegawa T, Hizawa K, Sano T. Dualcolour fluorescence in situ hybridization analysis of synovial sarcoma. J Pathol 1998;184:7-13.

9. Clark J, Rocques PJ, Crew AJ, Gill S, Shipley J, Chan AM, et al. Identification of novel genes, SYT and SSX, involved in the $t(X ; 18)(p 11.2 ; q 11.2)$ translocation found in human synovial sarcoma. Nat Genet 1994;7:502-8.

10. de Leeuw B, Balemans M, Olde Weghuis D, Geurts van Kessel A. Identification of two alternative fusion genes, SYTSSX1 and SYT-SSX2, in $\mathrm{t}(\mathrm{X} ; 18)(\mathrm{p} 11.2 ; \mathrm{q} 11.2)$-positive synovial sarcomas. Hum Mol Genet 1995;4:1097-9.

11. Crew AJ, Clark J, Fisher C, Gill S, Grimer R, Chand A, et al. Fusion of SYT to two genes, SSX1 and SSX2, encoding proteins with homology to the Kruppel-associated box in human synovial sarcoma. EMBO J 1995;14:2333-40.

12. de Leeuw B, Balemans M, Geurts van Kessel A. A novel Kruppel-associated box containing the SSX gene (SSX3) on the human $X$ chromosome is not implicated in $t(X ; 18)$ positive synovial sarcomas. Cytogenet Cell Genet 1996;73: 179-83.

13. Gure AO, Tureci O, Sahin U, Tsang S, Scanlan MJ, Jager E, et al. SSX: a multigene family with several members transcribed in normal testis and human cancer. Int J Cancer 1997;72:965-71.

14. dos Santos NR, Torensma R, de Vries TJ, Schreurs MW, de Bruijn DR, Kater-Baats E, et al. Heterogeneous expression of the SSX cancer/testis antigens in human melanoma lesions and cêll lines. Cancer Res 2000;60:1654-62.

15. Tureci O, Chen YT, Sahin U, Gure AO, Zwick C, Villena C, et al. Expression of SSX genes in human tumors. Int J Cancer 1998;77:19-23.

16. Mancuso T, Mezzelani A, Riva C, Fabbri A, Dal Bo L, Sampietro G, et al. Analysis of SYT-SSX fusion transcripts and bcl-2 expression and phosphorylation status in synovial sarcoma. Lab Invest 2000;80:805-13.

17. Skytting B, Nilsson G, Brodin B, Xie Y, Lundeberg J, Uhlen M, et al. A novel fusion gene, SYT-SSX4, in synovial sarcoma. J Natl Cancer Inst 1999;91:974-5.

18. Brodin B, Haslam K, Yang K, Bartolazzi A, Xie Y, Starborg M, et al. Cloning and characterization of spliced fusion transcript variants of synovial sarcoma: SYT/SSX4, SYT/SSX4v, and SYT/SSX2v. Possible regulatory role of the fusion gene product in wild type SYT expression. Gene 2001;268:173-82.

19. Inagaki H, Nagasaka T, Otsuka T, Sugiura E, Nakashima N, Eimoto T. Association of SYT-SSX fusion types with proliferative activity and prognosis in synovial sarcoma. Mod Pathol 2000;13:482-8. 
20. Kawai A, Woodruff J, Healey JH, Brennan MF, Antonescu CR, Ladanyi M. SYT-SSX gene fusion as a determinant of morphology and prognosis in synovial sarcoma. N Engl J Med 1998;338:153-60.

21. Nilsson G, Skytting B, Xie Y, Brodin B, Perfekt R, Mandahl N, et al. The SYT-SSX1 variant of synovial sarcoma is associated with a high rate of tumor cell proliferation and poor clinical outcome. Cancer Res 1999;59:3180-4.

22. Fisher C. Synovial sarcoma: ultrastructural and immunohistochemical features of epithelial differentiation in monophasic and biphasic tumors. Hum Pathol 1986;17:9961008.

23. Kwok S, Higuchi R. Avoiding false positives with PCR. Nature 1989;339:237-8.

24. Lim FL, Soulez M, Koczan D, Thiesen HJ, Knight JC. A KRAB-related domain and a novel transcription repression domain in proteins encoded by SSX genes that are disrupted in human sarcomas. Oncogene 1998;17:2013-8.

25. dos Santos NR, de Bruijn DR, Kater-Baats E, Otte AP, van Kessel AG. Delineation of the protein domains responsible for SYT, SSX, and SYT-SSX nuclear localization. Exp Cell Res 2000;256:192-202.

26. dos Santos NR, de Bruijn DR, van Kessel AG. Molecular mechanisms underlying human synovial sarcoma development. Genes Chromosom Cancer 2001;30:1-14.

27. Sonobe H, Takeuchi T, Liag SB, Taguchi T, Yuri K, Shimizu K, et al. A new human synovial sarcoma cell line, HS-SY-3, with a truncated form of hybrid SYT/SSX1 gene. Int J Cancer 1999;82:459-64.

28. Nagai M, Tanaka S, Tsuda M, Endo S, Kato H, Sonobe H, et al. Analysis of transforming activity of human synovial sarcoma-associated chimeric protein SYT-SSX1 bound to chromatin remodeling factor hBRM/hSNF2 alpha. Proc Natl Acad Sci U S A 2001;98:3843-8.

29. Safar A, Wickert R, Nelson M, Neff JR, Bridge JA. Characterization of a variant SYT-SSX1 synovial sarcoma fusion transcript. Diagn Mol Pathol 1998;7:283-7.

30. Sanders ME, van de Rijn M, Barr FG. Detection of a variant SYT-SSX1 fusion in a case of predominantly epithelioid synovial sarcoma. Mol Diagn 1999;4:65-70.

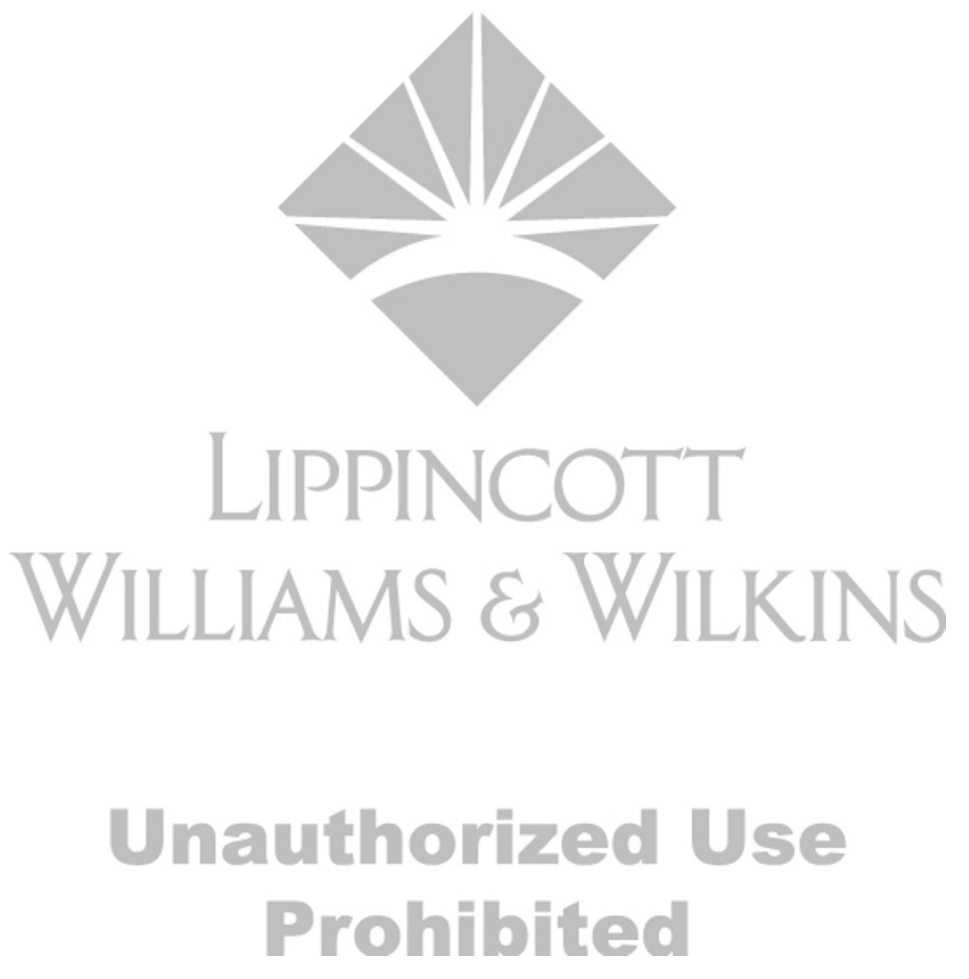

